\title{
Interleukin-7 improves T-cell recovery after experimental T-cell-depleted bone marrow transplantation in T-cell-deficient mice by strong expansion of recent thymic emigrants
}

\author{
Annoek E. C. Broers, Sandra J. Posthumus-van Sluijs, Hergen Spits, Bronno van der Holt, Bob Löwenberg, \\ Eric Braakman, and Jan J. Cornelissen
}

\begin{abstract}
Interleukin-7 (IL-7) has been shown to enhance thymic output of newly developed T cells following bone marrow transplantation (BMT) in mice. In addition, IL-7 may affect peripheral expansion of T cells. In order to study the relative contribution of thymopoiesis versus peripheral T-cell expansion in the setting of compromised thymopoiesis, we have applied IL-7 in an experimental stem cell transplantation model using $\mathrm{T}$ cell-deficient $\mathrm{RAG}-1^{-/-}$ mice. C57BL/6 RAG-1-1- mice received transplants of syngeneic T-cell-depleted
\end{abstract}

(TCD) bone marrow (Ly5.1) with or without supplemented T cells (Ly5.2). IL-7 was administered until day 63 after BMT. Peripheral blood $\mathrm{T}$ - and $\mathrm{B}$-cell recovery was quantified by flow cytometry and thymopoiesis was studied by quantification of T-cell receptor rearrangement excision circles (TRECs). In mice receiving a T-cellreplete BMT, IL-7 selectively expanded mature CD45.2 $2^{+} \mathrm{T}$ cells without affecting the recovery of new bone marrow-derived CD45.1 ${ }^{+} \mathrm{T}$ cells. In contrast, IL-7 significantly enhanced the recovery of bone marrow-derived $T$ cells after TCD BMT. Quantification of TRECs in mice receiving a TCD BMT revealed that enhanced T-cell recovery following IL-7 treatment resulted from a strong expansion of newly developed naive $T$ cells. These results suggest that peripheral expansion of recent thymic emigrants or mature $T$ cells may be a preferential mechanism by which IL-7 enhances T-cell recovery after BMT. (Blood. 2003;102:1534-1540)

() 2003 by The American Society of Hematology

\section{Introduction}

Hematopoietic stem cell transplantation is an established modality to treat a variety of hematologic disorders. Although epithelial barriers, granulocytes, and natural killer cells are usually restored within 1 month following transplantation, $\mathrm{T}$ and $\mathrm{B}$ lymphocytes may be deficient for a prolonged period of time. ${ }^{1}$ In particular, the recovery of naive $\mathrm{CD} 4{ }^{+} \mathrm{CD} 45 \mathrm{RA}^{+} \mathrm{T}$ cells is extremely slow. ${ }^{2-4}$ The slow reconstitution of naive $\mathrm{CD} 4^{+} \mathrm{T}$ cells in older patients may be related to the natural involution of the thymus, and thymic output may be further compromised by radiotherapy and graft-versus-host disease (GVHD) ${ }^{5-8}$ Until recently, thymic output of T cells could be quantified only by the measurement of $\mathrm{CD}^{+}{ }^{+} \mathrm{CD} 45 \mathrm{RA}^{+}$naive $\mathrm{T}$ cells in the peripheral blood. Enumerating naive $\mathrm{CD}^{+} \mathrm{T}$ cells by flow cytometry may serve as a surrogate marker, but naive $\mathrm{CD} 4^{+} \mathrm{T}$ cells may persist in the circulation for a prolonged period of time before converting to a memory phenotype. ${ }^{9}$ Recently, episomal DNA circles generated during rearrangement of the gene segments encoding the T-cell receptor (TCR) have been proposed as markers for thymic output. ${ }^{10-13}$ These circles, named TCR rearrangement excision circles (TRECs), are stable, are not duplicated during mitosis, and are diluted with each cellular division. ${ }^{14}$ Recent studies have shown an accurate assessment of thymic output by the quantification of these TRECs in humans. ${ }^{8,10-16}$ We and others recently developed a real-time quantitative polymerase chain reaction (PCR) of TRECs in mice and showed accurate assessment of peripheral blood and thymic TRECs, which appeared dependent on age, strain, and thymic function. ${ }^{17,18}$
New therapeutic agents to enhance immune recovery are currently being developed. Interleukin-7 (IL-7) has been identified as a potent thymopoietic agent. ${ }^{19,20}$ IL-7 is a pleiotropic cytokine, which is indispensable for murine $\mathrm{T}$ and $\mathrm{B}$ lymphopoiesis and essential for human T-cell development. ${ }^{21-23}$ In addition, recent studies have shown that IL-7 plays an essential role in the homeostatic expansion of peripheral naive $\mathrm{T}$ cells and the expansion of memory T cells. ${ }^{24-26}$ These properties of IL-7 have led to the idea that exogenous IL-7 may overcome immunodeficiencies after transplantation both by accelerating thymic T-cell development and by expanding the peripheral pool of newly developed $\mathrm{T}$ cells. Indeed, both direct effects of IL-7 on thymopoiesis and expansion of peripheral T-cell numbers have been shown in different experimental models. ${ }^{27-31}$ However, the differential contribution of central versus peripheral T-cell recovery remains poorly understood. In nonhuman primates, effects of IL-7 on peripheral T-cell numbers by expanding naive and nonnaive $\mathrm{T}$ cells predominated an effect on thymopoiesis. ${ }^{32,33}$ In mice, however, administration of IL-7 increases both thymopoiesis and peripheral T-cell expansion following stem cell transplantation. ${ }^{26,28,31}$ At present, it is unknown whether IL-7 preferably promotes thymopoiesis or rather expands recent thymic emigrants or mature $\mathrm{T}$ cells in mice in the setting of compromised thymopoiesis. To address these questions, we applied IL-7 in an experimental bone marrow transplantation (BMT) model using T-cell-deficient RAG-1 ${ }^{-1-}$ mice. We show that
From the Department of Hematology, Erasmus MC/Daniel den Hoed Cancer Center, Rotterdam, the Netherlands; Department of Immunology, Dutch Cancer Institute, Amsterdam, the Netherlands; and Department of Statistics, Erasmus MC/Daniel den Hoed Cancer Center, Rotterdam, the Netherlands.

Submitted November 6, 2002; accepted April 7, 2003. Prepublished online as Blood First Edition Paper, April 24, 2003; DOI 10.1182/blood-2002-11-3349.
Reprints: Jan J. Cornelissen, Department of Hematology, Erasmus MC/Danie den Hoed Cancer Center, PO Box 5201, 3075 EA Rotterdam, the Netherlands: e-mail: j.cornelissen@erasmusmc.nl.

The publication costs of this article were defrayed in part by page charge payment. Therefore, and solely to indicate this fact, this article is hereby marked "advertisement" in accordance with 18 U.S.C. section 1734

(C) 2003 by The American Society of Hematology 
IL-7 preferably affects the expansion of peripheral $\mathrm{T}$ cells, either recent thymic emigrants or mature T cells.

\section{Materials and methods}

\section{Mice}

C57BL/6-RAG- $1^{-1-}$ mice, originally obtained from The Jackson Immunoresearch Laboratories (Bar Harbor, ME), and C57BL/6-Ly5.1 mice were bred at the Experimental Animal Center, Erasmus University Medical Center, Rotterdam, the Netherlands. C57BL/6-Ly5.2 mice were purchased from Charles River Laboratories (Wilmington, MA). Male and female 10to 14-week-old C57BL/6-RAG- $1^{-/-}$mice were used as recipients of $5 \times 10^{6}$ syngeneic CD45.1 ${ }^{+}$bone marrow cells from 10- to 12-week-old C57BL/6-Ly5.1 mice. $\mathrm{T}$ cells $\left(\mathrm{CD} 45.2^{+}\right)$were obtained from syngeneic C57BL/6-Ly5.2 mice. Mice were maintained under specific pathogen-free conditions in individual ventilated cages with acidified water and antibiotics. All animal procedures were performed in accordance with protocols approved by the local Committee for Animal Experiments.

\section{Bone marrow transplantation}

To obtain bone marrow cells, femurs of donor mice were crushed, passed through a nylon mesh, washed, and resuspended in RPMI medium (Gibco BRL, Grand Island, NY) containing 1\% fetal calf serum (FCS; Gibco BRL) and $2 \mathrm{mM}$ ethylenediaminetetraacetic acid (EDTA; Sigma, St Louis, MO). Bone marrow cells were depleted of $\mathrm{T}$ cells by incubation with rat antimouse CD4 (YTS191, YTA312) and rat antimouse CD8 (YTS169) monoclonal antibodies $(\mathrm{mAbs})^{34}$ for 30 minutes on ice, followed by a wash and incubation with goat antirat immunoglobulin $\mathrm{G}(\mathrm{IgG})$ microbeads (Miltenyi Biotec, Bergisch Gladbach, Germany) for 15 minutes at $4^{\circ} \mathrm{C}$. Labeled cells were removed by passing the cell suspension over a magnetic column, using the AutoMacs according to the manufacturer's instructions (Miltenyi Biotec). The efficacy of T-cell depletion was checked by flow cytometry and was always found to be more than $2 \log$. To obtain T cells, spleens were harvested, dispersed, and counted by a Sysmex microcellcounter (Toa Medical Electronics, Kobe, Japan). T cells were purified from donor spleens by negative selection using a cocktail of non-T-cell monoclonal antibodies according to the manufacturer's instructions (StemSep; Stemcell Technologies, Vancouver, BC, Canada). Purity of the T-cell fraction was confirmed by flow cytometry and was always found to exceed 95\%. Nonirradiated recipient $\mathrm{RAG}-1^{-1-}$ mice received $5 \times 10^{6} \mathrm{~T}$-celldepleted $\mathrm{CD} 45.1^{+}$bone marrow cells either alone or together with $0.5 \times 10^{6}$ purified CD $45.2^{+} \mathrm{T}$ cells. Cells were suspended in phosphatebuffered saline (PBS) containing 1\% FCS and transplanted by tail-vein infusion ( $0.5 \mathrm{~mL}$ volume per infusion).

\section{Interleukin-7}

Recombinant human IL-7 was kindly provided by Dr Michel Morre (Cytheris, Vanves, France). The biological activity of each batch of recombinant human IL-7 was determined by a ${ }^{3} \mathrm{H}$-thymidine incorporation proliferation assay using the murine IL-7-dependent B-cell line 2E8 obtained from American Type Culture Collection (ATCC; Manassas, VA). Between day 7 and day 63 after BMT, recipient mice received IL-7 twice daily by subcutaneous injection at a dose of 500 or $2500 \mathrm{ng}$ per injection, diluted in PBS plus 1\% FCS at $0.25 \mathrm{~mL}$ per injection. Control mice received injections of PBS plus 1\% FCS at $0.25 \mathrm{~mL}$ per injection, twice daily.

\section{Flow cytometric analysis}

At serial time points following transplantation, blood was collected from the murine retro-orbital plexus. Absolute numbers of peripheral blood $\mathrm{T}$ and B cells were determined by a single-platform flow cytometric assay: inclusion of a calibrated number of fluorescent beads (Flow-Count Fluorospheres; Beckman Coulter, Fullerton, CA) in a lyse no-wash technique allows for direct calculation of absolute number of labeled cells per microliter of blood according to the ratio between beads and labeled cells. mAbs used for flow cytometric analysis were fluorescein isothiocyanate (FITC)-conjugated anti-CD3 $\epsilon$, anti-CD45.1, and anti-CD44 (Becton Dickinson, San Jose, CA); phycoerythrin (PE)-conjugated anti-CD4, antiCD19, anti-CD45.1, anti-CD45.2, anti-CD69, anti-NK1.1, anti-Gr-1, and anti-MAC-1 (Becton Dickinson); anti-CD25, anti-CD45R (B220), and anti-CD8 (Beckman Coulter); Cy-Chrome-conjugated anti-CD45, allophycocyanin (APC)-conjugated anti-CD3 $\epsilon$, anti-CD4, and anti-CD25 (Becton Dickinson); biotin-conjugated anti-CD25 and anti-CD45.2 (Becton Dickinson). Streptavidin-PE and streptavidin-APC (Becton Dickinson) were used to detect biotinylated monoclonal antibodies. T-cell receptor (TCR) V $\beta$ usage was assessed by staining with FITC-conjugated TCR V $32, \mathrm{~V} \beta 3$, $\mathrm{V} \beta 4, \mathrm{~V} \beta 5.1, \mathrm{~V} \beta 5.2, \mathrm{~V} \beta 6, \mathrm{~V} \beta 7, \mathrm{~V} \beta 8.1, \mathrm{~V} \beta 8.2, \mathrm{~V} \beta 8.3, \mathrm{~V} \beta 9, \mathrm{~V} \beta 10 \mathrm{~b}, \mathrm{~V} \beta 11$, $\mathrm{V} \beta 12, \mathrm{~V} \beta 13, \mathrm{~V} \beta 14$, and $\mathrm{V} \beta 17 \mathrm{a}$ (mouse $\mathrm{V} \beta$ TCR screening panel, Becton Dickinson). Staining with 7-amino actinomycin D (7-AAD) was performed for single-cell suspensions of bone marrow and thymus to exclude dead cells. Thymuses were harvested at days 28 and 43 following transplantation. To obtain a single-cell suspension, thymuses were minced with scissors and passed through a nylon mesh. Cells were washed and counted by a Sysmex microcellcounter (Toa Medical Electronics). Absolute numbers of thymic cell subsets were determined by multiplying the number of nucleated cells by the percentage of positive cells for the indicated cell surface marker(s). Flow cytometric analysis was performed using a FACScan or FACSCalibur (Becton Dickinson). Flow cytometric data were collected and analyzed using CELLQuest software (Becton Dickinson).

\section{Real-time quantitative PCR (RQ-PCR) of sjTRECs}

DNA was purified from blood, isolated splenic $\mathrm{CD} 4^{+}$and $\mathrm{CD} 8^{+} \mathrm{T}$ cells, and thymic cell suspensions using the QIAamp DNA mini kit (Qiagen, Hilden, Germany) according to manufacturer's instructions. Signal joint (sj) TRECs were detected with our recently developed 5' nuclease based RQ-PCR assay using the ABI PRISM 7700 sequence detector (Applied Biosystems, Foster City, CA). ${ }^{23}$ In short, the PCR was performed in a $50 \mu \mathrm{L}$ reaction containing $1.0 \times$ TaqMan Buffer A (Applied Biosystems), $4 \mathrm{mM}$ $\mathrm{MgCl}_{2}, 500 \mu \mathrm{M}$ dNTPs (Amersham Biosciences, Piscataway, NJ), 1.25 units AmpliTaq Gold (Applied Biosystems), $300 \mathrm{nM}$ forward and reverse primers, $200 \mathrm{nM}$ probe, and $5 \mu \mathrm{L}$ isolated DNA. All reactions were performed in duplicate or triplicate. PCR conditions were $95^{\circ} \mathrm{C}$ for 10 minutes followed by 40 cycles of $95^{\circ} \mathrm{C}$ for 15 seconds and $60^{\circ} \mathrm{C}$ for 1 minute. Sequences of the sjTREC primers and probe used were as follows: forward primer, 5' CCAAGCTGACGGCAGGTTT-3'; reverse primer, 5'-AGCATGGCAAGCAGCACC-3'; probe, FAM-5'-TGCTGTGTGCCCTGCCCTGCC-3'-TAMRA(Eurogentec, Seraing, Belgium). To compensate for variations in input DNA we used the constant gene segment of the TCRA gene $(\mathrm{C} \alpha)$ as endogenous reference gene. The sequences of the primers and probe were as follows: forward primer, 5'-TGACTCCCAAATCAATGTG-3'; reverse primer, 5'-GCAGGTGAAGCTTGTCTG-3'; probe, FAM-5'-TGCTGGACATGAAAGCTATGGA-3'-TAMRA (Applied Biosystems). These 2 primer combinations resulted in amplicons of 130 and 136 base pair (bp), respectively, without nonspecific background bands as visualized on an agarose gel. SjTREC copies in the peripheral blood, spleen, and thymus were calculated as recently reported ${ }^{18}$ and expressed per $10^{5} \mathrm{CD}^{+} \mathrm{T}$ lymphocytes or per $10^{5} \mathrm{CD} 45.1^{+}$donor derived thymocytes.

\section{Statistical analysis}

Numbers of peripheral $\mathrm{CD} 3^{+} \mathrm{T}$ cells (and their subsets) as well as $\mathrm{CD} 19^{+} \mathrm{B}$ cells were compared between groups of IL-7-treated and PBS-treated mice at different time points after transplantation using the Student $t$ test. All significant results were confirmed by the Wilcoxon rank-sum test. All $P$ values are 2-sided and a significance level of $\alpha$ less than or equal to .05 was used. Numbers of TREC copies per $10^{5} \mathrm{~T}$ cells were also compared between groups of mice by Student $t$ test. 

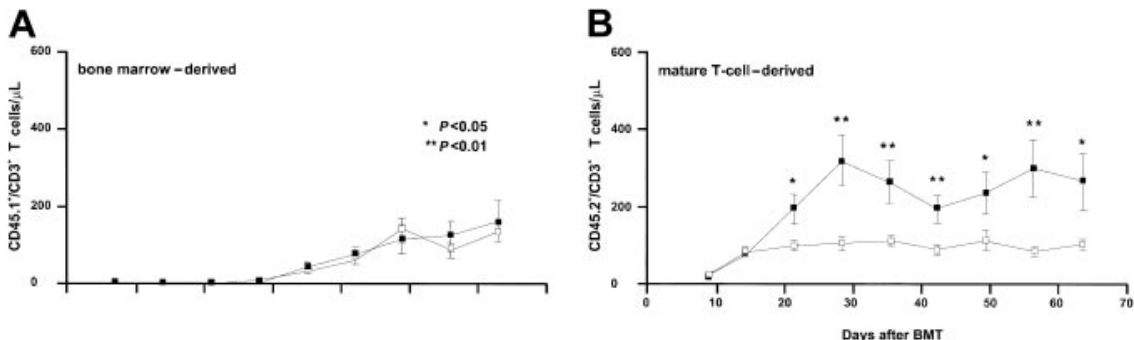

Figure 1. IL-7 expands native T-cells after T-cell-replete BMT. Bone marrow-derived newly developed T cells (CD45.1) and mature (supplemented) T cells (CD45.2) were distinguished by CD45-isoform and their absolute numbers were determined by flow cytometry at weekly intervals in peripheral blood samples. RAG- $1^{-1-}$ mice $(n=30)$ received $5 \times 10^{6}$ syngeneic T-cell-depleted CD45.1 ${ }^{+}$bone marrow cells, supplemented with $0.5 \times 10^{6} \mathrm{CD} 45.2^{+} \mathrm{T}$ cells. IL-7 was administered subcutaneously (500 ng twice daily) from day 7 to day 63. T-cell recovery was studied weekly, using single-platform flow cytometry, in PBS-treated mice $(\square, n=15)$ and IL-7-treated mice $(\square, n=15)$. Mean absolute numbers $( \pm \mathrm{SE})$ are shown for $\mathrm{CD} 45.1^{+} / \mathrm{CD}^{+}(\mathrm{A})$ and $\mathrm{CD} 45.2^{+} / \mathrm{CD}^{+}(\mathrm{B}) \mathrm{T}$ cells.

\section{Results}

\section{IL-7 preferentially expands mature T cells after T-cell-replete BMT}

After a T-cell-replete BMT, T cells may originate either from bone marrow-derived thymic precursors or from mature T cells infused with the bone marrow graft. To evaluate the effects of IL-7 on these 2 sources of $\mathrm{T}$ cells, we subjected $\mathrm{RAG}-1^{-1-}$ mice to syngeneic T-cell-depleted (TCD) BMT from C57BL/6-Ly5.1 donor mice supplemented with CD45.2 mature splenic T cells. Bone marrowderived newly developed T cells (CD45.1) and mature (supplemented) $\mathrm{T}$ cells (CD45.2) were distinguished by CD45 isoform and their absolute numbers were determined by flow cytometry at weekly intervals in peripheral blood samples (Figure 1). Administration of IL-7 from day 7 onward led to an early (day 21) and sustained increase of $\mathrm{CD} 45.2^{+} / \mathrm{CD}^{+} \mathrm{T}$ cells as compared with PBS treatment. Newly developed, bone marrow-derived, CD $45.1^{+} /$ $\mathrm{CD}^{+} \mathrm{T}$ cells appeared in the peripheral blood from day 35 onward. IL-7 administration did not enhance the recovery of bone marrowderived T cells (Figure 1A), and increasing the dose of IL-7 5-fold did not accelerate or enhance the recovery of those newly developed CD $45.1^{+} / \mathrm{CD}^{+} \mathrm{T}$ cells (results not shown). Absolute numbers of $\mathrm{CD} 45.2^{+} / \mathrm{CD}^{+} \mathrm{T}$ cells measured approximately 200 $\mathrm{T}$ cells/ $\mu \mathrm{L}$ from day 21 onward, resulting in a persistent chimerism ratio of more than 1 in favor of $\mathrm{CD} 45.2$ mature $\mathrm{T}$ cells. The relative contribution of $\mathrm{CD}^{+} / \mathrm{CD} 3^{+}$T-helper cells and $\mathrm{CD} 8^{+} / \mathrm{CD} 3^{+}$cytotoxic $\mathrm{T}$ cells to the total absolute number of $\mathrm{CD}^{+} \mathrm{T}$ cells was assessed in time (Table 1). An early high CD4/CD8 T-cell ratio after T-cell-replete BMT gradually decreased from 2.0 to 0.7 in PBS-treated mice and from 2.7 to 1.0 in IL-7-treated mice. Higher numbers of $\mathrm{CD}^{+} / \mathrm{CD}^{+} \mathrm{T}$ cells versus $\mathrm{CD} 8^{+} / \mathrm{CD}^{+} \mathrm{T}$ cells were induced by IL-7 than by PBS early after BMT and until day 42 following T-cell-replete BMT.

Table 1. $\mathrm{CD}^{+} / \mathrm{CD}^{+}+\mathrm{T}$-cell ratios after BMT

\begin{tabular}{lllcll}
\hline $\begin{array}{c}\text { Type of BMT and } \\
\text { treatment }\end{array}$ & 14 & 28 & 42 & 56 & 63 \\
\cline { 2 - 6 } & & & & & \\
\hline $\begin{array}{c}\text { T-cell-replete } \\
\text { IL-7 }\end{array}$ & 2.7 & 2.8 & 1.7 & 1.1 & 1.0 \\
PBS & 2.0 & 1.4 & 1.5 & 1.2 & 0.7 \\
TCD & - & - & 1.0 & 1.9 & 3.1 \\
IL-7 & - & - & 1.3 & 1.5 & 1.9 \\
PBS & - & & & & \\
\hline
\end{tabular}

Shown are ratios of absolute median numbers of peripheral blood $\mathrm{CD} 3^{+} \mathrm{CD} 4$ and $\mathrm{CD}^{+}{ }^{+} \mathrm{CD} 8^{+} \mathrm{T}$ cells $/ \mu \mathrm{L}$ per group of mice $(n=6)$. - indicates not applicable.

\section{IL-7 enhances T-cell recovery in RAG-1 ${ }^{-/-}$mice after TCD BMT}

As IL-7 appeared to exert no enhancing effect on the recovery of bone marrow-derived $\mathrm{T}$ cells following T-cell-replete BMT, we next wished to evaluate the effect of IL-7 on the recovery of newly developed T cells following TCD BMT. RAG- $1^{-1-}$ mice received a TCD BMT followed by IL-7 or PBS administration from day 7 onward until the end of the experiment (Figure 2). As in mice receiving a T-cell-replete BMT, bone marrow-derived CD45.1 ${ }^{+}$/ $\mathrm{CD}^{+} \mathrm{T}$ cells appeared in the peripheral blood by 35 days after BMT. IL-7 did not accelerate the early recovery of newly developed T cells, but, in contrast to T-cell-replete BMT, the ultimate level of recovery was enhanced by IL-7. The recovery of $\mathrm{CD}^{+} \mathrm{T}$ cells to more than $200 / \mu \mathrm{L}$ was achieved by day 42 in IL-7-treated mice, whereas the number of T cells in PBS-treated control mice did not achieve that level by day 63 . Increasing the dose of IL-7 5-fold (to $2500 \mathrm{ng}$ twice daily) did not enhance the level of recovery, nor did it shorten the time lag between BMT and first signs of T-cell recovery (results not shown). As in recipients of replete grafts, high $\mathrm{CD} 4 / \mathrm{CD} 8 \mathrm{~T}$-cell ratios were observed in recipients of TCD BMT (Table 1). The highest ratio was observed in recipients treated with $\mathrm{IL}-7$, indicating the generation of approximately 2 to 3 times higher numbers of $\mathrm{CD} 4^{+} \mathrm{T}$ cells than of CD8 ${ }^{+} \mathrm{T}$ cells.

\section{Thymopoiesis versus peripheral T-cell expansion after TCD BMT}

Treatment with IL-7 resulted in enhanced recovery of newly developed bone marrow-derived $\mathrm{T}$ cells after TCD BMT. To

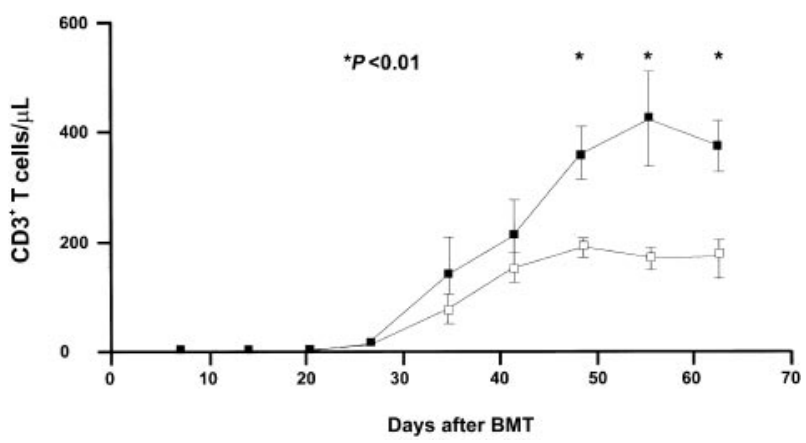

Figure 2. IL-7 enhances T-cell recovery after TCD BMT. RAG-1 $1^{-/-}$mice received TCD BMT followed by IL-7 or PBS administration from day 7 until the end of the experiment. RAG- $1^{-1-}$ mice received $5 \times 10^{6}$ syngeneic TCD CD $45.1^{+}$bone marrow cells. IL-7 was given subcutaneously twice daily $(2 \times 500 \mathrm{ng})$ from day 7 to day 63 . T-cell recovery was evaluated weekly in mice treated with PBS $(\square, n=21)$ and mice treated with IL-7 $(\mathbf{\square}, \mathrm{n}=21)$. Mean absolute numbers $( \pm \mathrm{SE})$ of $\mathrm{CD}^{+} \mathrm{T}$ cells/ $\mu \mathrm{L}$ are shown. 
evaluate whether that effect was due to increased thymopoiesis or expansion of recent thymic emigrants after export from the thymus, we assessed TREC frequencies directly in thymocytes as well as in the peripheral blood. Groups of mice $(n=9)$ were killed at days 28 and 43 after TCD BMT for analysis of the thymus by flow cytometric analysis and by RQ-PCR of TRECs. As shown in Figure 3 , IL-7 administration resulted in a moderate but not significant increase in the frequency of TREC copies per $10^{5}$ donor-derived CD $45.1^{+}$thymocytes at day 28 . PBS-treated recipients showed a median frequency of 1990 (range, 0-6396) TREC copies per $10^{5}$ CD $45.1^{+}$thymocytes, as compared with a median frequency of 3093 (range, 0-5064) TREC copies per $10^{5} \mathrm{CD} 45.1^{+}$thymocytes in IL-7-treated mice $(P=.1)$. In addition, the median number of TREC copies per $10^{5} \mathrm{CD} 45.1^{+}$thymocytes was not affected by IL-7 at day 43 after transplantation (median [range] for PBS vs IL-7, 6693 [4225-7095] vs 5217 [2961-9699]). Absolute numbers of donor-derived CD45.1 ${ }^{+}$thymocytes were not significantly increased by IL-7 at days 28 and 43. Apart from TREC analysis, thymocyte subset distribution was evaluated by flow cytometry. The relative distribution of $\mathrm{CD} 44^{+} / \mathrm{CD} 25^{-}, \mathrm{CD} 44^{+} / \mathrm{CD} 25^{+}$, and $\mathrm{CD} 44^{+} / \mathrm{CD} 25^{+}$pro- $\mathrm{T}$ cells was not affected by IL-7, nor did IL-7 change the percentages of $\mathrm{CD}^{+} / \mathrm{CD}^{+}$(double-positive) or singlepositive $\mathrm{T}$ cells.

In addition to thymocyte TREC levels, peripheral blood samples were evaluated at 42,49 , and 56 days after BMT for the presence of $\mathrm{TREC}^{+} / \mathrm{CD}^{+}{ }^{+}$lymphocytes. Healthy C57BL/6 mice may show 2000 to 3000 TREC copies per $10^{5} \mathrm{CD}^{+} \mathrm{T}$ cells at the age of 3 to 6 months, as recently reported. ${ }^{23}$ Those levels were not observed in RAG- $1^{-1-}$ mice, which received a syngeneic C57BL/6 T-celldepleted $\left(\right.$ RAG- $1^{+/+}$) BMT. Peripheral blood TREC frequencies were below the detection limit at day 42 in 4 of 5 PBS-treated mice, only 1 showing 2576 TREC copies per $10^{5} \mathrm{~T}$ cells, and were also undetectable in 4 of 6 IL-7-treated mice. As shown in Figure 4, 2 IL-7-treated mice had detectable TREC frequencies (1036 and 846 TREC copies per $10^{5} \mathrm{CD}^{+}$T-lymphocytes) at day 42 after BMT. However, while absolute numbers of $\mathrm{CD} 45.1^{+} / \mathrm{CD}^{+} \mathrm{T}$ cells in these IL-7-treated mice increased in time, TREC frequencies dropped to a lower or even undetectable level.

Taken together, our results indicate that IL-7 induces expansion of newly developed $\mathrm{T}$ cells after export from the thymus. Spleens were harvested in separate groups of mice $(n=10)$ for additional analysis of activation status of peripheral $\mathrm{T}$ cells as well as analysis of TREC frequencies at day 43 after transplantation. Among PBS-treated mice, a median of $7.2 \%$ (range, $3.8 \%-10.4 \%$ ) of $\mathrm{CD}^{+}$

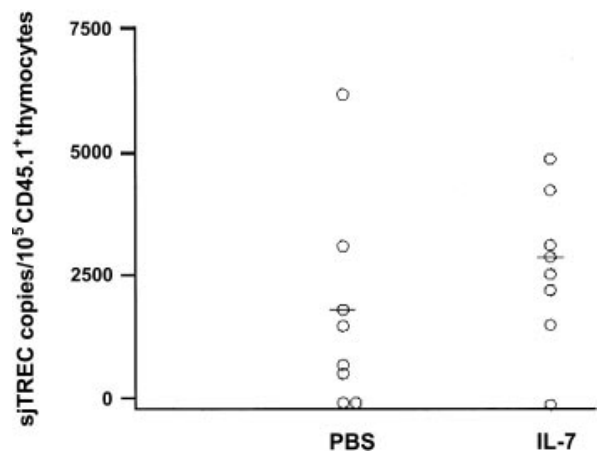

Figure 3. IL-7 moderately affects thymopoiesis. IL-7 administration resulted in a moderate but not significant increase in the frequency of TREC copies per $10^{5}$ donor-derived CD45.1+ thymocytes at day 28. Recipients of T-cell-depleted BMT treated with IL-7 $(n=9)$ or PBS $(n=9)$ were killed at day 28 and thymuses were evaluated for numbers of TREC copies per $10^{5}$ bone marrow-derived CD45.1 ${ }^{+}$ thymocytes. Horizontal bars indicate medians.

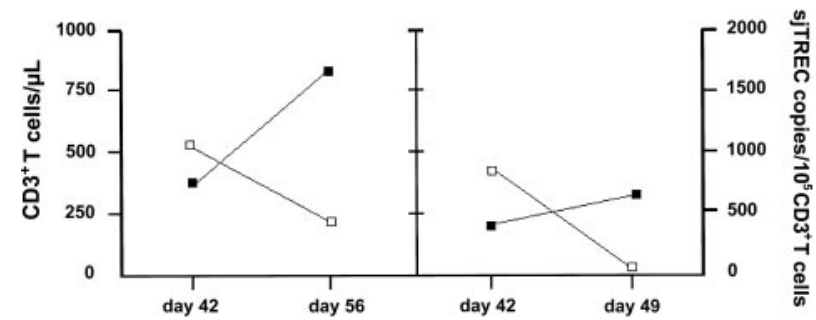

Figure 4. Individual results of 2 IL-7-treated mice after BMT. Peripheral blood numbers of $\mathrm{CD}^{+} \mathrm{T}$ cells $/ \mu \mathrm{L}(\mathbf{\square})$ and numbers of TREC copies per $10^{5} \mathrm{CD} 3^{+} \mathrm{T}$ cells ( $\square$ ) were evaluated following TCD BMT and IL-7 treatment.

T cells were $\mathrm{CD}_{25} 5^{+}$, and a median of $6.3 \%$ (range, $1.8 \%-10.8 \%$ ) of all $\mathrm{T}$ cells were $\mathrm{CD} 69^{+}$. Comparable percentages were observed in IL-7-treated mice: of all $\mathrm{CD}^{+}$donor T cells, a median of $6.1 \%$ (range, $2.2 \%-12.1 \%$ ) were $\mathrm{CD}_{2} 5^{+}$and a median of $7.2 \%$ (range, $2.6 \%-14.5 \%$ ) were $\mathrm{CD}^{2} 9^{+}$. Following selection of $\mathrm{CD}^{+}$and $\mathrm{CD}^{+} \mathrm{T}$ cells and DNA isolation, TREC copies were fewer than 50 per $100000 \mathrm{~T}$ cells in all IL-7-treated mice, whereas the frequency of TREC copies detected in PBS-treated mice varied between 112 and 267 per $10^{5} \mathrm{CD}^{+} \mathrm{T}$ lymphocytes, again suggesting dilution of TREC-positive T cells by IL-7.

\section{IL-7 treatment does not skew the T-cell repertoire}

As antigen-driven expansion of peripheral $\mathrm{T}$ cells may result in a skewed and limited T-cell repertoire, ${ }^{39}$ we evaluated the effect of IL-7 on the T-cell receptor repertoire of the reconstituted peripheral blood $\mathrm{T}$ cells by flow cytometric analysis of the expression of 15 TCR V $\beta$ families at day 70 following stem cell transplantation. Both recipients of TCD grafts and recipients of T-cell-replete stem cell transplants showed a broad T-cell receptor repertoire, independent of the administration of IL-7. Results are shown in Figure 5.

\section{IL-7 accelerates B-cell recovery in RAG-1 ${ }^{-/-}$mice following syngeneic TCD and T-cell-replete BMT}

Apart from its effect on T-cell progenitors and mature T cells, IL-7 is known to promote B-cell development in mice. ${ }^{25}$ The effect of IL-7 on B-cell progenitors was studied concurrently in RAG-1 $1^{-1-}$ mice receiving bone marrow grafts depleted of $\mathrm{T}$ cells and in RAG-1 $1^{-/-}$mice receiving T-cell-replete BMT. As shown in Figure 6 , IL-7 administration resulted in accelerated B-cell recovery in mice receiving a TCD BMT. A level of $50 \mathrm{CD} 19^{+} \mathrm{B}$ cells $/ \mu \mathrm{L}$ blood was reached at day 21 in IL-7-treated mice, whereas PBS-treated mice did not reach the mean level of $50 \mathrm{CD} 19^{+} \mathrm{B}$ cells at day 63 following transplantation. The effect of IL-7 following

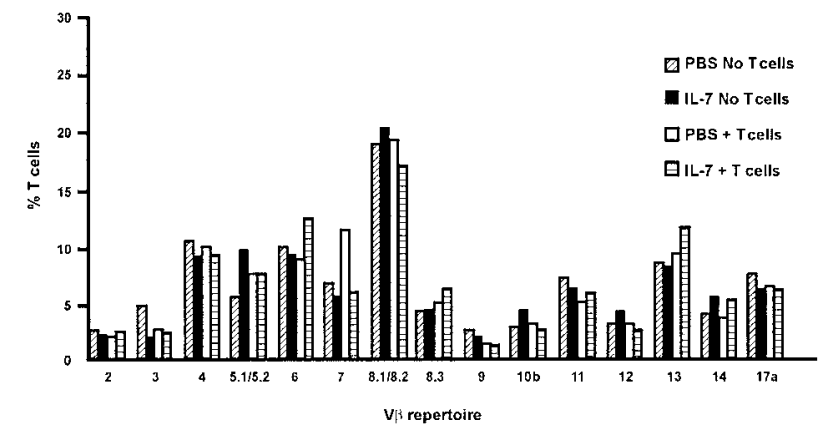

Figure 5. IL-7 treatment does not skew the T-cell repertoire. Following T-cell-

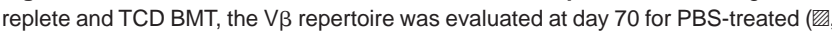
$\square$ ) and IL-7-treated $(\mathbf{\square}$, 目) recipients. Percentages per V $\beta$ type are expressed as percentage of all $\mathrm{V} \beta$ types per treatment modality. 

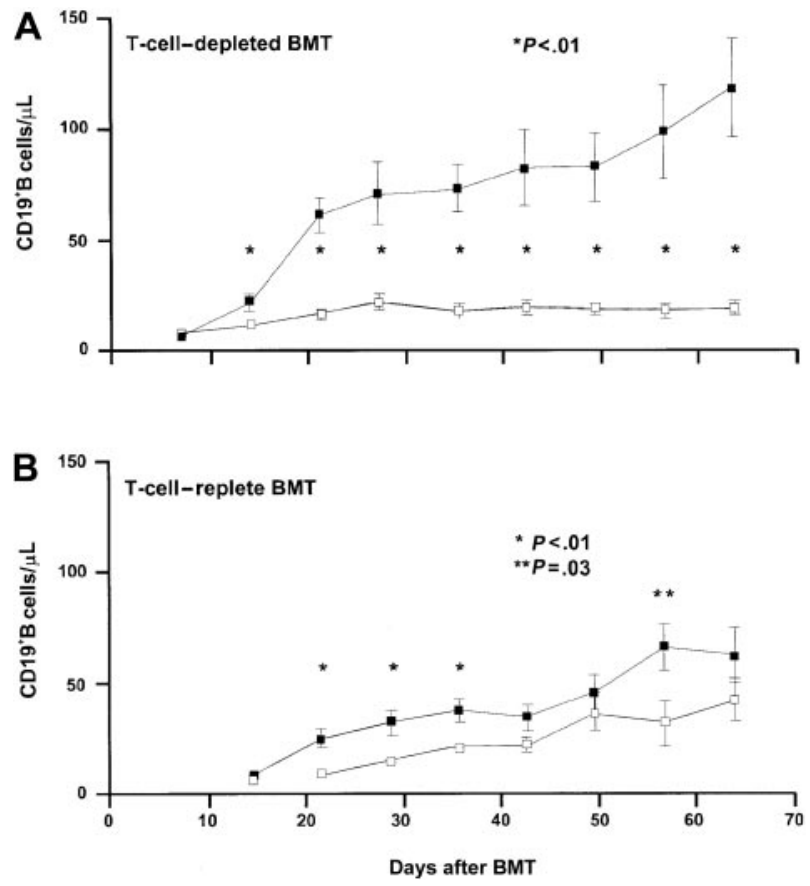

Figure 6. IL-7 administration resulted in accelerated B-cell recovery in mice receiving T-cell-depleted BMT. Recovery of $C D 19^{+} \mathrm{B}$ cells $/ \mu \mathrm{L}$ was evaluated after T-cell-depleted (panel A, 2 groups of 21 mice each) and T-cell-replete (panel B, 2 groups of 15 mice each) BMT. Groups of mice were treated with PBS ( $\square$ ) or IL-7 (ם) at a dose of $500 \mathrm{ng}$ twice daily on days 7 to 63 . Absolute mean numbers ( $\pm \mathrm{SE}$ ) are depicted.

T-cell-replete transplantation was significantly less. The mean level of $50 \mathrm{CD} 19^{+} \mathrm{B}$ cells $/ \mu \mathrm{L}$ was not reached until 49 days following transplantation in IL-7-treated mice. Increasing the dose of IL-7 5-fold, to $2500 \mathrm{ng}$ twice daily, did not accelerate or enhance the recovery of B cells following T-cell-replete BMT (Figure 7). However, the higher dose of IL-7 did transiently affect recipient B-cell progenitor expansion, as demonstrated by an immediate sharp increase of CD45.2 $2^{+} / \mathrm{CD} 19^{+} \mathrm{B}$ cells, followed by a sharp decrease, concurrently with expansion of donor CD45.1 ${ }^{+} / \mathrm{CD} 19^{+}$ $\mathrm{B}$ cells and donor T cells (Figure 7).

\section{Discussion}

Thymic output of newly developed $\mathrm{T}$ cells may be severely impaired in recipients of hematopoietic stem cell grafts. Especially, adult patients experiencing chronic GVHD following allogeneic stem cell transplantation may show extremely retarded and reduced recovery of naive T cells. ${ }^{8,15}$ The quantification of those $\mathrm{T}$ cells by PCR of TRECs has facilitated the monitoring of thymic output and highlighted the deficient function of the thymus after allogeneic stem cell transplantation (SCT). ${ }^{8,10-16}$ The adverse clinical consequences of impaired recovery of $\mathrm{T}$ cells, both $\mathrm{CD} 4^{+} \mathrm{T}$-helper cells and $\mathrm{CD}^{+}$cytotoxic $\mathrm{T}$ cells, has been demonstrated in studies showing a correlation between opportunistic infections and low T-cell numbers after allogeneic SCT. ${ }^{35,36}$ It may be anticipated that new therapeutic approaches that accelerate T-cell recovery may be of considerable clinical benefit. One of these approaches may be the use of exogenous IL-7, a cytokine involved in thymopoiesis as well as in peripheral T-cell expansion. ${ }^{19,20,31,32,37,38}$ In order to study the relative contribution of each of these effects of IL-7, we applied IL-7 in T cell-deficient RAG-1 ${ }^{-1-}$ mice following T-cell-depleted or T-cell-replete BMT. The model allows the evaluation of T-cell recovery in time in a setting of partially impaired thymopoiesis. We show that peripheral expansion of $\mathrm{T}$ cells is a dominant effect of exogenous IL-7 after T-cell-replete BMT. Moreover, after TCD BMT, a strong expansion of bone marrow-derived recent thymic emigrants also predominated over an effect on thymopoiesis. These effects in mice with compromised thymopoiesis compare well to recent observations in nonhuman primates. ${ }^{32,33}$ No effects on thymopoiesis were observed in irradiated baboons receiving a TCD autologous stem cell graft followed by IL-7 therapy, ${ }^{33}$ and the peripheral effects of IL-7 also predominated over an effect on thymopoiesis in healthy juvenile cynomolgus monkeys. ${ }^{32}$

Recipients of replete grafts, which were not treated with IL-7, predominantly repopulated their peripheral blood $\mathrm{T}$ cells by expansion of mature $\mathrm{T}$ cells infused with the bone marrow graft. Newly developed bone marrow-derived $\mathrm{T}$ cells appeared after 5 weeks and their number gradually increased, accompanied by an increase in bone marrow-derived T-cell chimerism in time. The cumulative number of $\mathrm{T}$ cells in mice receiving either a TCD or a T-cell-replete graft (without IL-7 treatment) was estimated at approximately $200 \mathrm{CD}^{+} \mathrm{T}$ cells/ $\mu \mathrm{L}$ (Figures 1 and 2) at day 60 and did not differ between these 2 groups. These results support the hypothesis formulated by Mackall et al that both mature T cells and recent thymic emigrants may compete for available T-cell active cytokines that support clonal expansion in the periphery. ${ }^{31}$ Mature $\mathrm{T}$ cells added to the graft may have inhibited the recovery of newly developed bone marrow-derived $\mathrm{T}$ cells. This was especially evident in mice treated with IL-7. While both recipients of TCD grafts and recipients of replete grafts recovered their peripheral T-cell numbers up to 300 to $400 \mathrm{CD}^{+} \mathrm{T}$ cells $/ \mu \mathrm{L}$ following treatment with IL-7, bone marrow-derived $\mathrm{T}$ cells contributed to that cumulative number to only a minor degree following T-cellreplete SCT. This may be explained by effective competition for available IL-7 by the mature $\mathrm{T}$ cells added to the graft. A preferential use of available IL-7 by those $\mathrm{T}$ cells was further supported by the down-regulation of B-cell lymphopoiesis in recipients of replete versus TCD grafts (Figure 6). The preferential use of IL-7 by rapidly proliferating peripheral T cells may be explained by synergistic or amplifying effects of IL-7 and other cytokines involved in T-cell proliferation and activation. IL-7 has been shown to induce and to act in concert with IL-2, and IL-7 synergizes with IL-12 in inducing T-cell proliferation, T-cell activation, and the development of a type I immune response. ${ }^{39-45}$ Such amplifying effects induced by IL-7 may be beneficial in the development of an immune response toward potentially lethal infectious micro-organisms, but such effects may be harmful in the development of graft-versus-host reactions after allogeneic SCT. Although a recent study reported no evidence for enhancement of
A

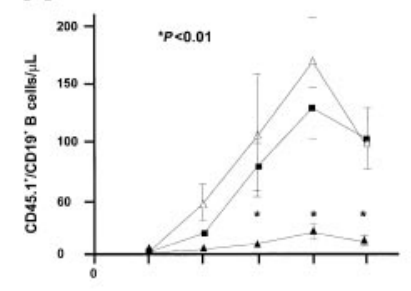

B

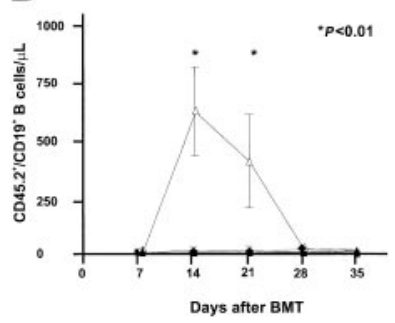

Figure 7. Effect of IL-7 following T-cell-replete transplantation. Recovery of CD45.1 $1^{+} / \mathrm{CD} 19^{+}$(recipient) and CD45.2+/CD19+ (donor) B-cell numbers was evaluated in recipients of T-cell-replete BMT followed by treatment with IL-7 at a dose of 2500 ng twice daily $(\triangle, n=5)$, IL-7 at a dose of 500 ng twice daily $(\mathbf{\square}, n=9)$, or PBS $(\boldsymbol{\Lambda}, \mathrm{n}=9)$. $P$ values shown correspond to both the comparison of $2500 \mathrm{ng} \mathrm{IL-7}$ versus PBS and the comparison of 500 ng IL-7 versus PBS. 
GVHD by IL-7, ${ }^{46}$ a study by Sinha et al showed that IL-7 may lower the threshold T-cell dose required to induce GVHD as well as enhance lethality and tissue damage in an experimental murine model ${ }^{47}$ Both the latter results and our findings suggest that IL-7 should be restricted to the setting of T-cell depletion and that proinflammatory effects by IL-7 on alloreactive T cells should be avoided.

The proinflammatory effects of IL-7 may also have contributed to the preferential expansion of $\mathrm{CD}^{+}{ }^{+} \mathrm{T}$ cells as opposed to $\mathrm{CD} 8^{+}$ $\mathrm{T}$ cells, as observed following both T-cell-replete and TCD BMT. A key intermediate in that effect may be IL-27, which is a recently identified proinflammatory cytokine that synergizes with IL-12 to trigger interferon- $\gamma\left(\right.$ IFN- $\gamma$ ) production of naive $\mathrm{CD} 4^{+} \mathrm{T}$ cells and, more important, selectively drives rapid clonal expansion of naive $\mathrm{CD}^{+}{ }^{+} \mathrm{T}_{\text {cells. }}{ }^{48}$ Apart from IL-7-treated mice, high $\mathrm{CD} 4^{+} / \mathrm{CD}^{+}$ ratios were also observed in control mice (Table 1), which may be explained by a proinflammatory background already present in these severely immunodeficient RAG- $1^{-/-}$recipients. Clinically, a strong correlation has been shown between CD4 counts and IL-7 levels, ${ }^{26,49}$ and weaker correlations between IL-7 levels and CD8 ${ }^{+}$ T cells. In particular, strong inverse correlations between IL-7 and $\mathrm{CD}_{2} 2 \mathrm{~L}^{+} \mathrm{CD} 45 \mathrm{RA}^{+} \mathrm{CD} 4^{+}$naive $\mathrm{T}$ cells have been observed in patients with HIV. ${ }^{26}$ The relationship may suggest a feedback mechanism between IL-7 and CD4 ${ }^{+}$T-cell counts. Clearly, the relationship between IL-7 and $\mathrm{CD}^{+}{ }^{+} \mathrm{T}$ cells needs to be studied in more detail to elucidate the mechanism responsible for a preferential outgrowth of $\mathrm{CD} 4^{+} \mathrm{T}$ cells as observed in the present study and to clarify the mechanism by which $\mathrm{CD}^{+}$lymphopenia may increase IL-7 levels in lymphopenic patients.

We planned to study the effects of IL-7 in T cell-deficient mice, which exhibit compromised thymic function after transplantation of normal bone marrow. As previously reported, RAG- $1^{-1-}$ mice exhibit a small thymus with residual arrested thymopoiesis in the cortex and an involuted medulla, which may partially regenerate following restoration of thymopoiesis. ${ }^{50,51}$ Persistent impaired thymic function after transplantation was evidenced by a relatively low frequency of TREC ${ }^{+}$thymocytes. Using a similar TREC assay, Sempowski et al showed 4000 to 8000 TREC copies per 100000 thymocytes in healthy BALB/c mice. ${ }^{18}$ We observed a median copy number of 2000 per 100000 thymocytes, which compares well to the lower numbers Sempowski et al observed in older mice (aged 90 weeks and older). Although IL-7 moderately increased donor thymopoiesis and the frequency of $\mathrm{TREC}^{+}$thymocytes, a normalization of the TREC copy number was not achieved. In contrast, Okamoto et al recently found that exogenous IL-7 may strongly enhance the generation of TRECs in vitro and in vivo, using normal human thymus of fetal origin. ${ }^{52}$ Our results suggest that IL-7 may be necessary, but not sufficient, to fully restore thymopoiesis in the setting of impaired medullary function as exhibited by RAG-1 ${ }^{-/-}$ mice. Also, the deficient thymopoiesis observed in older adult mice was not fully restored by exogenous IL-7 in 2 experimental studies evaluating IL-7 in aged $\mathrm{C} 57 \mathrm{BL} / 6 \mathrm{mice}^{31}$ or $\mathrm{BALB} / \mathrm{c}$ mice, ${ }^{18}$ although Pido-Lopez et al observed augmented thymopoiesis in their model.$^{53}$ Together, these results suggest that additional factors are required to fully restore thymic function in $\mathrm{RAG}-1^{-1-}$ mice and aged mice with involuted thymuses. A putative additional factor may be stem cell factor (SCF), a cytokine, which may act in concert with IL-7 at a very early stage of thymopoiesis. ${ }^{54}$ Furthermore, the recent identification of the murine thymic epithelial stem cell may provide new insights into the essential nursing requirements provided by the epithelium in thymopoiesis. ${ }^{55,56}$

In conclusion, although exogenous IL-7 may improve thymopoiesis, the cytokine is preferentially consumed by rapidly proliferating $\mathrm{T}$ cells in the periphery, including recent thymic emigrants and mature $\mathrm{T}$ cells. These results suggest that potential clinical applications may have particular promise in the setting of T-cell depletion in order to optimally profit from the effects on thymopoiesis and expansion of recent thymic emigrants and to avoid expansion and activation of potential harmful alloreactive T cells.

\section{References}

1. Storek J, Witherspoon RP. Immunological reconstitution after hemopoietic stem cell transplantation. In: Atkinson K, ed. Clinical Bone Marrow and Blood Stem Cell Transplantation: A Reference Textbook. 2nd ed. Cambridge, United Kingdom: Cambridge University Press; 2000:111-146.

2. Martinez C, Urbano-Ispizua A, Rozman C, et al. Immune reconstitution following allogeneic peripheral blood progenitor cell transplantation: comparison of recipients of positive $\mathrm{CD} 34^{+}$selected grafts with recipients of unmanipulated grafts. Exp Hematol. 1999;27:561-568.

3. Behringer D, Bertz H, Schmoor C, Berger C, Dwenger A, Finke J. Quantitative lymphocyte subset reconstitution after allogeneic hematopoietic transplantation from matched related donors with $\mathrm{CD} 34^{+}$selected PBPC grafts, unselected PBPC grafts or BM grafts. Bone Marrow Transplant. 1999;24:295-302.

4. Storek J, Dawson MA, Storer B, et al. Immune reconstitution after allogeneic marrow transplantation compared with blood stem cell transplantation. Blood 2001;97:3380-3389.

5. Weinberg K, Annett G, Kashyap A, Lenarsky C, Forman SJ, Parkman R. The effect of thymic function on immunocompetence following bone marrow transplantation. Biol Blood Marrow Transplant. 1995;1:18-23.

6. Small TN, Papadopoulos EB, Boulad F, et al. Comparison of immune reconstitution after unrelated and related T-cell depleted bone marrow transplantation: effect of patient age and donor leukocyte infusions. Blood. 1999;93:467-480.
7. Roux E, Dumont-Girard F, Starobinski M, et al. Recovery of immune reactivity after T-cell depleted bone marrow transplantation depends on thymic activity. Blood. 2000;96:2299-2303.

8. Weinberg K, Blazar BR, Wagner JE, et al. Factors affecting thymic function after allogeneic hematopoietic stem cell transplantation. Blood. 2001;97: 1458-1466.

9. Tough DF, Sprent J. Turnover of naive- and memory-phenotype T-cells. J Exp Med. 1994; 179:1127-1135.

10. Douek DC, McFarland RD, Keiser PH, et al. Changes in thymic function with age and during treatment of HIV infection. Nature. 1998;396:690695.

11. Douek DC, Vesico RA, Betts MR, et al. Assessment of thymic output in adults after haematopoietic stem cell transplantation and prediction of T-cell reconstitution. Lancet. 2000;355:18751881.

12. Kong $\mathrm{F}$, Chen $\mathrm{CH}$, Cooper MD. Thymic function can be accurately monitored by the level of recent T-cell emigrants in the circulation. Immunity. 1998;8:97-104

13. Hazenberg MD, Otto SA, Cohen Stuart JW, et al. Increased cell division but not thymic dysfunction rapidly affects the $\mathrm{T}$-cell receptor excision circle content of the naive T-cell population in HIV-1 infection. Nat Med. 2000;6:1036-1042.

14. Hazenberg MD, Verschuren MCM, Hamann D, Miedema F, Van Dongen JJM. T-cell receptor excision circles (TRECs) as markers for recent thy- mic emigrants. Basic aspects, technical approach, and guidelines for interpretation. $\mathrm{J} \mathrm{Mol}$ Med. 2001;79:631-640.

15. Lewin SR, Heller G, Zhang L, et al. Direct evidence for new T-cell generation by patients after either T-cell-depleted or unmodified allogeneic hematopoietic stem cell transplantations. Blood. 2002;100:2235-2242.

16. Hochberg EP, Chillemi AC, Wu CJ, et al. Quantitation of T-cell neogenesis in vivo after allogeneic bone marrow transplantation in adults. Blood. 2001;98:1116-1121.

17. Broers AEC, Meijerink JPP, Van Dongen JJM, et al. Quantification of newly developed T-cells in mice by real-time quantitative PCR of T-cell receptor rearrangement excision circles. Exp Hematol. 2002;30:745-750.

18. Sempowski GD, Gooding ME, Liao HX, Le PT, Haynes BF. T-cell receptor excision circle assessment of thymopoiesis in aging mice. Mol Immunol. 2002;38:841-848.

19. Fry TJ, Mackall CL. Interleukin-7: from bench to clinic. Blood. 2002;99:3892-3904

20. Spits H. Interleukin-7. In: Oppenheim JJ, Feldman R, eds. Cytokine Reference. London, United Kingdom: Academic Press; 2001:137-154.

21. Peschon JJ, Morrissey PJ, Grabstein KH, et al. Early lymphocyte expansion is severely impaired in interleukin 7 receptor-deficient mice. J Exp Med. 1994;180:1955-1960.

22. Von Freeden-Jeffry U, Vieira P, Lucian LA, McNeill T, Burdach SE, Murray R. Lymphopenia in 
interleukin (IL-7)-gene-deleted mice identifies $\mathrm{IL}-7$ as a nonredundant cytokine. J Exp Med. 1995;181:1519-1526.

23. Puel A, Ziegler SF, Buckley RH, Leonard WJ. Defective IL7R expression in $\mathrm{T}(-) \mathrm{B}(+) \mathrm{NK}(+)$ severe combined immunodeficiency. Nat Genet. 1998; 20:394-397.

24. Tan JT, Dudl E, LeRoy E, et al. IL-7 is critical for homeostatic proliferation and survival of naive T-cells. Proc Natl Acad Sci U S A. 2001;98:8732 8737.

25. Schluns KS, Kieper WC, Jameson SC, Lefrancois L. Interleukin-7 mediates the homeostasis of naive and memory CD8 T-cells in vivo. Nat Immunol. 2000;1:426-432.

26. Fry TJ, Connick E, Falloon J, et al. A potential role for interleukin-7 in T-cell homeostatasis. Blood. 2001;97:2983-2990.

27. Abdul-Hai A, Or R, Slavin S, et al. Stimulation of immune reconstitution by interleukin-7 after syngeneic bone marrow transplantation in mice. Exp Hematol. 1996;24:1416-1422.

28. Bolotin E, Smogorzewska M, Smith S, Widmer M Weinberg K. Enhancement of thymopoiesis after bone marrow transplantation by in vivo interleukin-7. Blood. 1996;88:1887-1894

29. Levy RB, Jones M, Hamilton BL, Paupe J, Horowitz T, Riley R. IL-7 drives donor T-cell proliferation and can costimulate cytokine secretion after MHC-matched allogeneic bone marrow transplantation. J Immunol. 1995;154:106-115.

30. Alpdogan O, Schmaltz C, Muriglan SJ, et al. Administration of interleukin-7 after allogeneic bone marrow transplantation improves immune reconstitution without aggravating graft-versus-host disease. Blood. 2001;98:2256-2265.

31. Mackall CL, Fry TJ, Bare C, Morgan P, Galbraith A, Gress RE. IL-7 increases both thymic-dependent and thymic-independent T-cell regeneration after bone marrow transplantation. Blood. 2001; 97:1491-1497.

32. Fry TJ, Moniuszko M, Creekmore S, et al. IL-7 therapy dramatically alters peripheral $\mathrm{T}$ cell homeostasis in normal and SIV infected non-human primates. Blood. 2003;101:2294-2299.

33. Storek J, Gillespy T III, Lu H, et al. Interleukin-7 improves CD4 T-cell reconstitution after autologous CD34 cell transplantation in monkeys. Blood. 2003;101:4209-4218.

34. Cobbold S, Martin G, Waldmann H. Monoclonal antibodies for the prevention of graft-versus-host disease and marrow graft rejection. The depletion of T-cell subsets in vitro and in vivo. Transplantation. 1986;42:239-247.

35. Storek J, Gooley T, Witherspoon RP, Sullivan KM, Storb R. Infectious morbidity in long-term survivors of allogenic marrow transplantation is associated with low CD4 T-cell counts. Am J Hematol. 1997:54:131-138.

36. Gratama JW, Van Esser JW, Lamers CH, et al. Tetramer-based quantification of cytomegalovirus (CMV)-specific CD8 + T lymphocytes in T-cell depleted stem cell grafts and after transplantation may identify patients at risk for progressive CMV infection. Blood. 2001;98:1358-1364.

37. Mackall CL, Bare CV, Granger LA, Sharrow SO, Titus JA, Gress RE. Thymic-independent T-cell regeneration occurs via antigen-driven expansion of peripheral T-cells resulting in a repertoire that is limited in diversity and prone to skewing. $\mathrm{J} \mathrm{Im}$ munol. 1996;156:4609-4616.

38. Fry TJ, Christensen BL, Komschlies KL, Gress RE, Mackall CL. Interleukin-7 restores immunity in athymic T-cell-depleted hosts. Blood. 2001;97: 1525-1533.

39. Gringhuis SI, de Leij LF, Verschuren EW, Borger $P$, Vellenga $E$. Interleukin-7 upregulates the interleukin-2-gene expression in activated human $T$ lymphocytes at the transcriptional level by enhancing the DNA binding activities of both nuclear factor of activated T-cells and activator protein-1. Blood. 1997;90:2690-2700.

40. Mehrotra PT, Grant AJ, Siegel JP. Synergistic effects of IL-7 and IL-12 on human T-cell activiation. J Immunol. 1995;154:5093-5102.

41. Borger P, Kauffman HF, Postma DS, Vellenga $E$. IL-7 differentially modulates the expression of IFN-gamma and IL-4 in activated human T lymphocytes by transcriptional and post-transcriptional mechanisms. J Immunol. 1996;156:13331338

42. Lynch $\mathrm{DH}$, Namen AE, Miller RE. In vivo evaluation of the effects of interleukins 2, 4 and 7 on en hancing the immunotherapeutic efficacy of antitumor cytotoxic T lymphocytes. Eur J Immunol. 1991;21:2977-2985.

43. Wiryana P, Bui T, Faltynek CR, Ho RJ. Augmentation of cell-mediated immunotherapy against herpes simplex virus by interleukins: comparison of in vivo effects of IL-2 and IL-7 on adoptively transferred T-cells. Vaccine. 1997;15:561-563.

44. Pavletic Z, Benyunes MC, Thompson JA, et al. Induction by interleukin-7 of lymphokine-activated killer activity in lymphocytes from autologous and syngeneic marrow transplant recipients before and after systemic interleukin-2 therapy. Exp Hematol. 1993;21:1371-1378.

45. Kondo M, Nonomura N, Miki T, et al. Enhancement of interleukin-2-induced lymphokine-activated killer activity by interleukin-7 against autologous human renal cell carcinoma. Oncology. 1998;55:588-593.

46. Alpdogan O, Schmalz C, Muriglan SJ, et al. Administration of interleukin-7 after allogeneic bone marrow transplantation improves immune reconstitution without aggravating graft-versus-host disease. Blood. 2001;98:2256-2265.

47. Sinha ML, Fry TJ, Fowler DH, Miller G, Mackall CL. Interleukin-7 worsens graft-vs-host disease. Blood. 2002;100:2642-2649.

48. Pflanz S, Timans JC, Cheung J, et al. IL-27, a heterodimeric cytokine composed of $\mathrm{EBI} 3$ and p28 protein, induces proliferation of naive CD4(+) T-cells. Immunity. 2002;16:779-790.

49. Napolitano LA, Grant RM, Deeks SG, et al. Increased production of IL-7 accompanies HIV-1 mediated T-cell depletion: implications for T-cell homeostasis. Nat Med. 2001;7:73-79.

50. Mombaerts P, lacomini J, Johnson RS, Herrup K, Tonegawa S, Papaioannou VE. RAG-1 deficient mice have no mature $B$ and $T$ lymphocytes. Cell. 1992;68:869-877.

51. Van Ewijk W, Holländer G, Terhorst C, Wang B. Stepwise development of thymic microenvironments in vivo is regulated by thymocyte subsets. Development. 2000;127:1583-1591.

52. Okamoto Y, Douek DC, McFarland RD, Koup RA. Effects of exogenous interleukin-7 on human thymus function. Blood. 2002;99:2851-2858.

53. Pido-Lopez J, Imami N, Andrew D, Aspinall R. Molecular quantitation of thymic output in mice and the effect of IL-7. Eur J Immunol. 2002;32: 2827-2836.

54. Rodewald HR, Ogawa M, Haller C, Waskow C, DiSanto JP. Pro-thymocyte expansion by c-kit and the common cytokine receptor $\gamma$-chain is essential for repertoire formation. Immunity. 1997;6: 265-272.

55. Gill J, Malin M, Holländer GA, Boyd R. Generation of a complete thymic microenvironment by $\mathrm{MTS}_{24}{ }^{+}$thymic epithelial cells. Nat Immunol. 2002;3:635-642.

56. Bennett AR, Farley A, Blair NF, Gordon J, Sharp L, Blackburn CC. Identification and characterization of thymic epithelial progenitor cells. Immunity. 2002;16:803-814 